\title{
La iglesia del barrio de Cavedone, Bolonia
}

\author{
The Cavedone district church, Bologna
}

Lorenzo Valla

https://doi.org/10.17979/aarc.2011.2.2.5069

El proyecto para la iglesia y el complejo parroquial del barrio de Cavedone, en Bolonia, se incluye dentro de un debate que ha animado el mundo arquitectónico italiano en el periodo denominado de la reconstrucción, desde la posguerra hasta la mitad de los años sesenta, aproximadamente. Este debate se interesaba por el proyecto de edificios para la construcción pública y popular, que respondiesen por completo a la finalidad social a la que estaban llamados.

Para elaborar el proyecto de esta iglesia, junto con el de todo el barrio, llegó el ingeniero-arquitecto Federico Gorio, figura importante del panorama nacional de aquel periodo por la contribución aportada precisamente a la búsqueda de una nueva identidad de la arquitectura italiana. Gorio, antes de abordar el proyecto de Bolonia, había trabajado al lado de Ludovico Quaroni en el barrio Ina Casa Tiburtino III, realizado en Roma (1950) ${ }^{1}$, y en el asentamiento rural La Martella ${ }^{2}$. Partidario del empirismo escandinavo, Gorio estuvo siempre profundamente convencido de que la forma no podía dejar de tener en cuenta el clima, el lugar y la historia, es decir la vida y costumbres de un pueblo.

El primer proyecto desarrollado para la iglesia muestra claramente la voluntad de responder en una doble vertiente: la necesidad laica, propia de un Estado en fase de renovación, de dar a la arquitectura una finalidad nueva que se expresase sobre todo a través de la revalorización de su función social, y la necesidad reli- giosa de restituir a la iglesia su vocación original de identificación con la comunidad, con la asamblea (la ecclesia). Se advertía la exigencia de una transformación formal de esta circunstancia.

La visión de los espacios comunitarios como instrumentos de cohesión social representa el valor compartido por dos personalidades: el arquitecto Federico Gorio y el cardenal Lercaro, que se encuentran al comienzo del proyecto de la iglesia y de la estructura anexa de la calle Cavedone.

El análisis del proyecto en cuestión, muchas veces replanteado y jamás realizado, ofrece al mismo tiempo la posibilidad de reinterpretar — reviviendo también la dificultad práctica de realización y comunicación- los elementos de un debate históricamente central para la arquitectura sacra italiana y europea de aquel periodo, y la posibilidad de valorar los elementos de modernidad y actualidad que presenta este proyecto, a la luz de la más reciente evolución del pensamiento religioso y laico a este respecto.

Desde los primeros croquis, al examinar la planificación de toda la zona que se remonta a julio de 1956, está clara por parte de Gorio la voluntad de insertar el conjunto eclesial en el interior de los diversos recorridos peatonales que estructuran el barrio de Cavedone, de incluir la iglesia dentro de la secuencia de diferentes episodios arquitectónicos que crean un recorrido, un barrio, una ciudad (Fig. 1). 


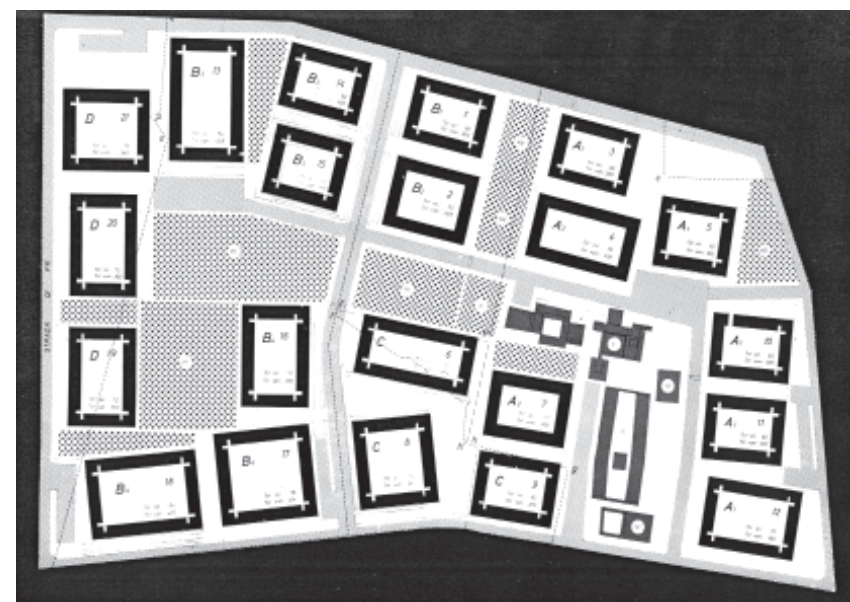

Fig. 1. Federico Gorio. Ordenación del barrio Cavedone (Bolonia), 1960.
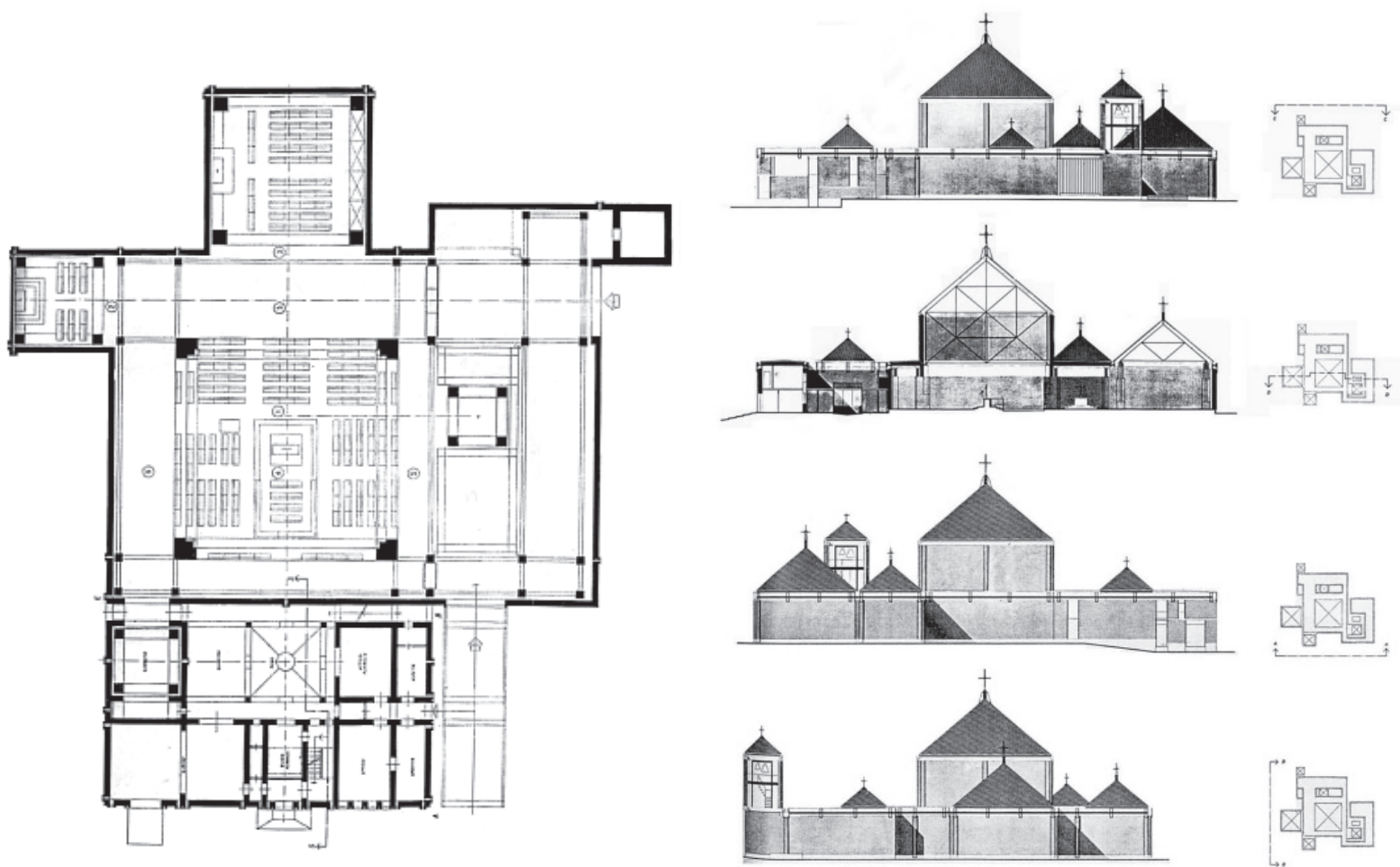

Figs. 2-3. Federico Gorio. Complejo parroquial en el barrio Cavedone (Bolonia, 1956/60). Planta y secciones. 


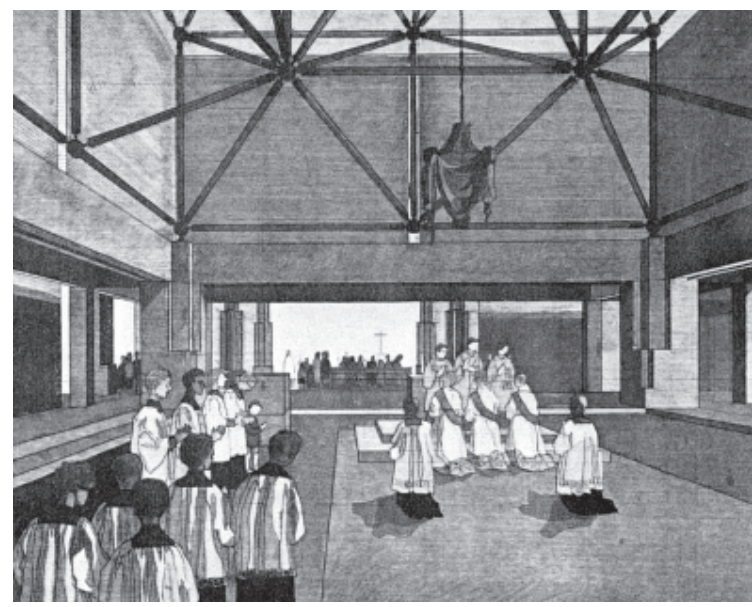

Fig. 4. Dibujo del espacio de la asamblea: el lugar.

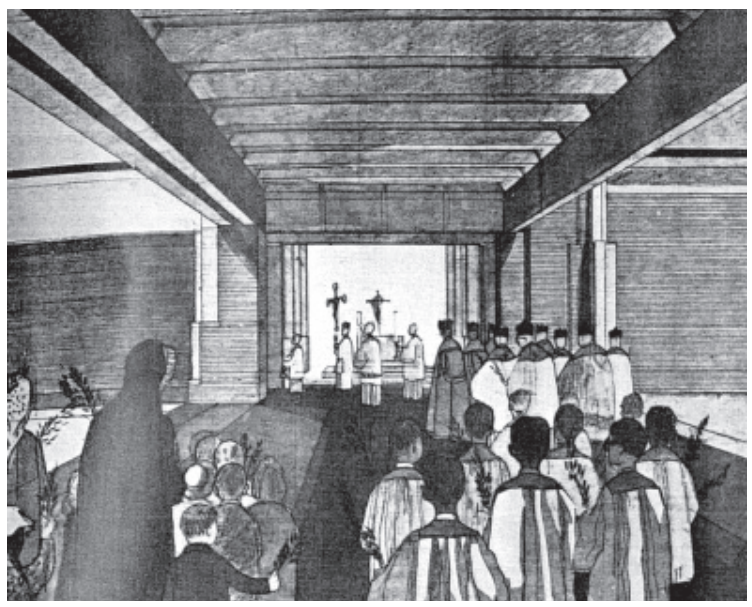

Fig. 5. Dibujo de uno de los recorridos procesionales: el recorrido.
De la memoria del proyecto emerge la intención, no sólo de insertar la iglesia en los recorridos peatonales que atraviesan el barrio, sino de hacer cambiar la misma meta de dichos recorridos: "La iglesia tiene la entrada principal hacia la plaza del barrio, mientras que la entrada secundaria se abre sobre un espacio menor delimitado por la casa rectoral y por los locales parroquiales, y alineado con la calle comercial peatonal. El conjunto de estos dos ambientes urbanos tiene la función de atrio y está dominado por el volumen del campanario al lado de la entrada principal» ${ }^{3}$.

$\mathrm{Al}$ recoger y reunir estos dos recorridos de entrada a la iglesia nos encontramos con un claustro. «Precede al espacio sacro un ambiente abierto de filtro y de silencio, una especie de nártex con un pequeño claustro y un campanario» ${ }^{4}$. En el interior de dicho espacio está bien visible el lugar del baptisterio, cuya precisa posición lo hace aparecer a mitad de todo el recorrido norte-sur del barrio que, una vez atravesadas las diferentes actividades y servicios públicos, desemboca en el interior de la iglesia. Este lugar es entendido por Gorio como posible ampliación del espacio sacro interior «bajo determinadas circunstancias y especiales exigencias» ${ }^{5}$, ampliación realizable por medio de paredes móviles o de vidrieras correderas, que constituyen el único elemento de separación entre el claustro y el espacio interior.

La cuestión de la flexibilidad y de la capacidad de la planta para adecuarse a las diversas exigencias del pro- grama está presente también en la disposición del espacio interior. «El ambiente interior o espacio sacro está concebido de forma que permita una amplia versatilidad de uso; puede albergar en efecto una numerosa congregación de fieles en la misa dominical y en las demás ceremonias solemnes, pero de igual modo contiene zonas más restringidas y apartadas para las misas menos concurridas, o para celebraciones concretas en las que participan pocos fieles ${ }^{6}$.

Todo el complejo eclesial parece concebido como una agregación de elementos arquitectónicos simples y estructuralmente independientes (Fig. 2-3), no diferentes de los utilizados como fundamento para los proyectos de la Weber House y de la Adler House, diseñados por Louis I. Kahn en 1954. Como igualmente fuerte aparece la influencia del Jewish Community Center de Trenton (New Jersey, 1954/58).

Sin embargo, dichos elementos arquitectónicos, coincidentes con los lugares litúrgicos e identificados espacialmente por cuatro pilastras y por una cubierta en pabellón, a diferencia de los edificios citados, se han recompuesto según una jerarquía precisa y se han orientado hacia el espacio principal que contiene el espacio de la asamblea, en el centro del cual se encuentra el altar.

Este ultimo espacio, también delimitado por cuatro potentes pilastras y cerrado con una amplia cubierta en pabellón, se convierte en el lugar fundamental de todo 


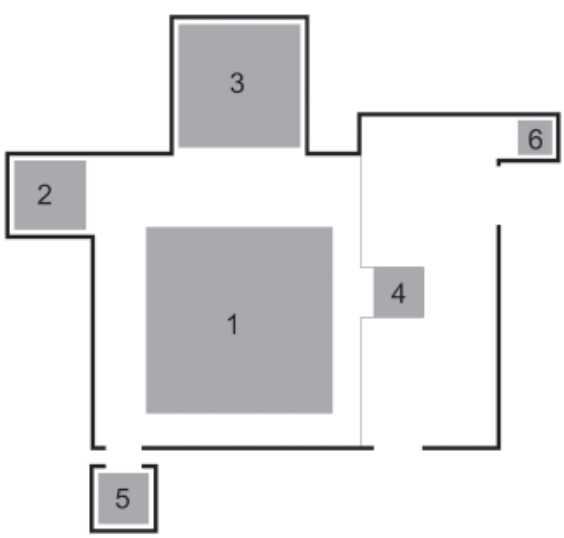

Fig. 6. Esquema de los ámbitos litúrgicos: 1 Aula; 2 Capilla del Santísimo; 3 Capilla penitencial; 4 Baptisterio; 5 Sacristía; 6 Campanario.

1
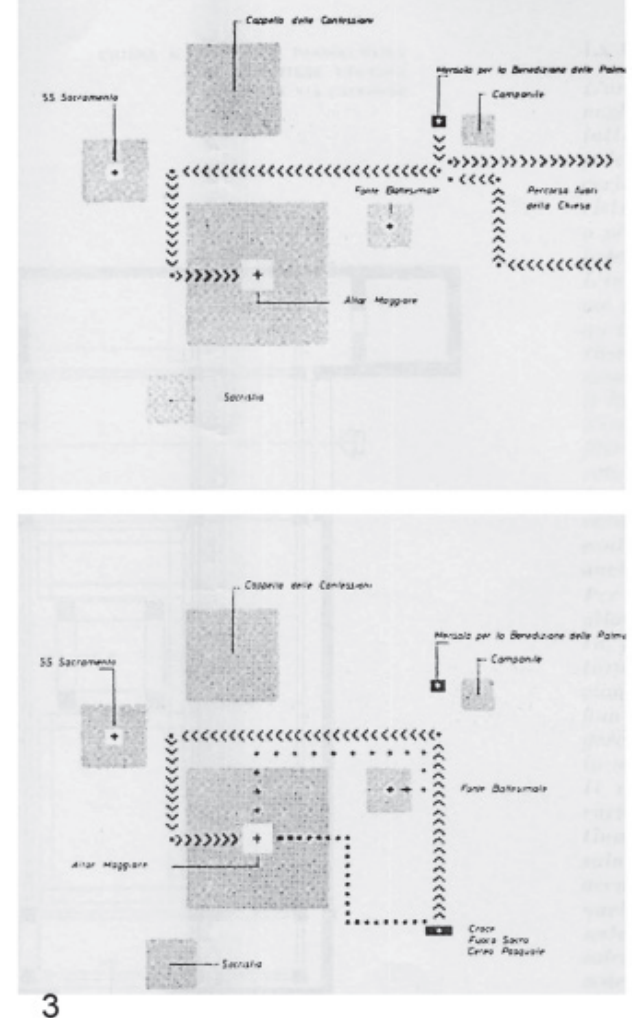

2
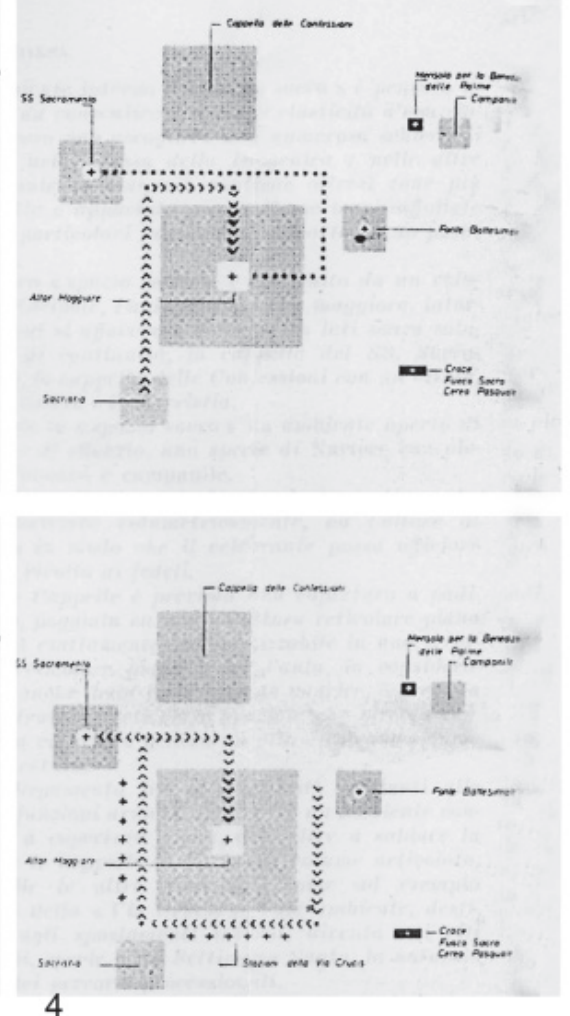

Fig. 7. Esquema de los distintos recorridos litúrgicos: 1 Domingo de Ramos; 2 Jueves Santo; 3 Sabado Santo; 4 Via Crucis. 


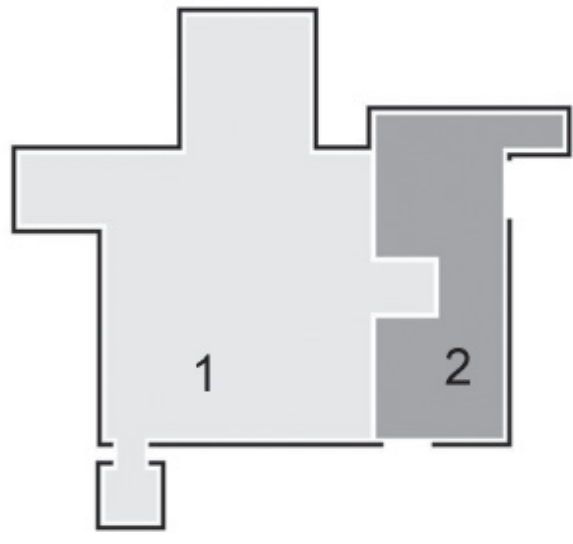

Fig. 8. Esquema: 1 Espacio interno; 2 Espacio externo.

el complejo a través de dos simples mecanismos: una mayor amplitud respecto a los demás y una sensible depresión del pavimento, que subraya el paso de un espacio al otro. Estos recursos lo convierten en el centro de toda la composición.

En esta planimetría de la parcela se encuentran, reelaborados, los dos arquetipos de la forma arquitectónica: el espacio direccional y el espacio central, el recorrido y el lugar (Fig. 4-5). La iglesia se ha concebido como un agregado de estas dos variantes espaciales básicas en la organización del espacio físico, resultando así un conjunto extremadamente dinámico. Gorio proyecta un plano policéntrico (Fig. 6), donde los espacios individuales —como la capilla del Santísimo Sacramento, la capilla penitencial, el baptisterio y la sacristía - mantienen su autonomía espacial. Su espacio se ha definido claramente, pero al mismo tiempo cada espacio se ha subordinado al elemento central -el principal—: la asamblea (Fig. 7).

El recinto, que constituye un atractivo recuerdo de la arquitectura de los orígenes, es el elemento polivalente en el interior del proyecto: la estructura que separa un exterior - evidenciado como espacio en el cual retirarse para subrayar la sacralidad del rito- del lugar interior en el que aquél se celebra, pero al mismo tiempo la estructura que une los lugares sagrados con los lugares funcionales para lo sagrado (Fig. 8).

De hecho, todo el complejo interior al recinto está a

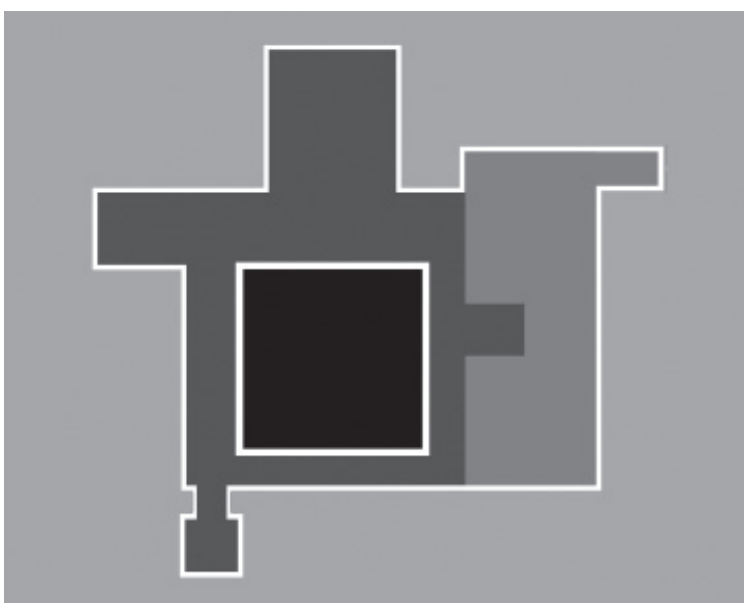

Fig. 9. Esquema de la dimensión íntima que se conquista viniendo del exterior: el espacio publico; en en interior: el lugar de la asamblea.

su vez formado por un exterior y un interior dialogando entre sí: el espacio exterior es el claustro; el espacio interior es la nave. El muro del recinto circunda y envuelve a ambos, uniéndolos entre sí y separándolos a la vez del exterior. El muro protege del entorno exterior, recoge y encierra a todos los elementos funcionales para la vida de la congregación mediante el escalonamiento de las distintas fases del rito y mediante los distintos momentos que marcan la vida del miembro de la comunidad. En el recinto se encuentran la capilla, la sacristía, el baptisterio, la nave y el claustro?.

De este último espacio cubierto, interpretado como elemento externo y de enlace entre las partes, se ha subrayado su importancia a través de la utilización de una reja con vidrios coloreados, utilizada como medio de separación de los otros espacios de culto. La permeabilidad de este lugar natural, la presencia de una delimitación física pero no corpórea, señala la demarcación - más que la clausura - de un lugar importante para la vida del creyente y para la celebración del culto. En este sentido, es particularmente evidente la referencia a la cristiandad de los primeros tiempos: el diálogo entre los espacios destinados a la celebración del culto, pero al mismo tiempo la creación de elementos de frontera que los mantengan separados y divididos según grados, niveles y modos de la celebración.

Gorio afronta con mucha sensibilidad el tema del umbral de entrada, poniendo su atención en los meca- 


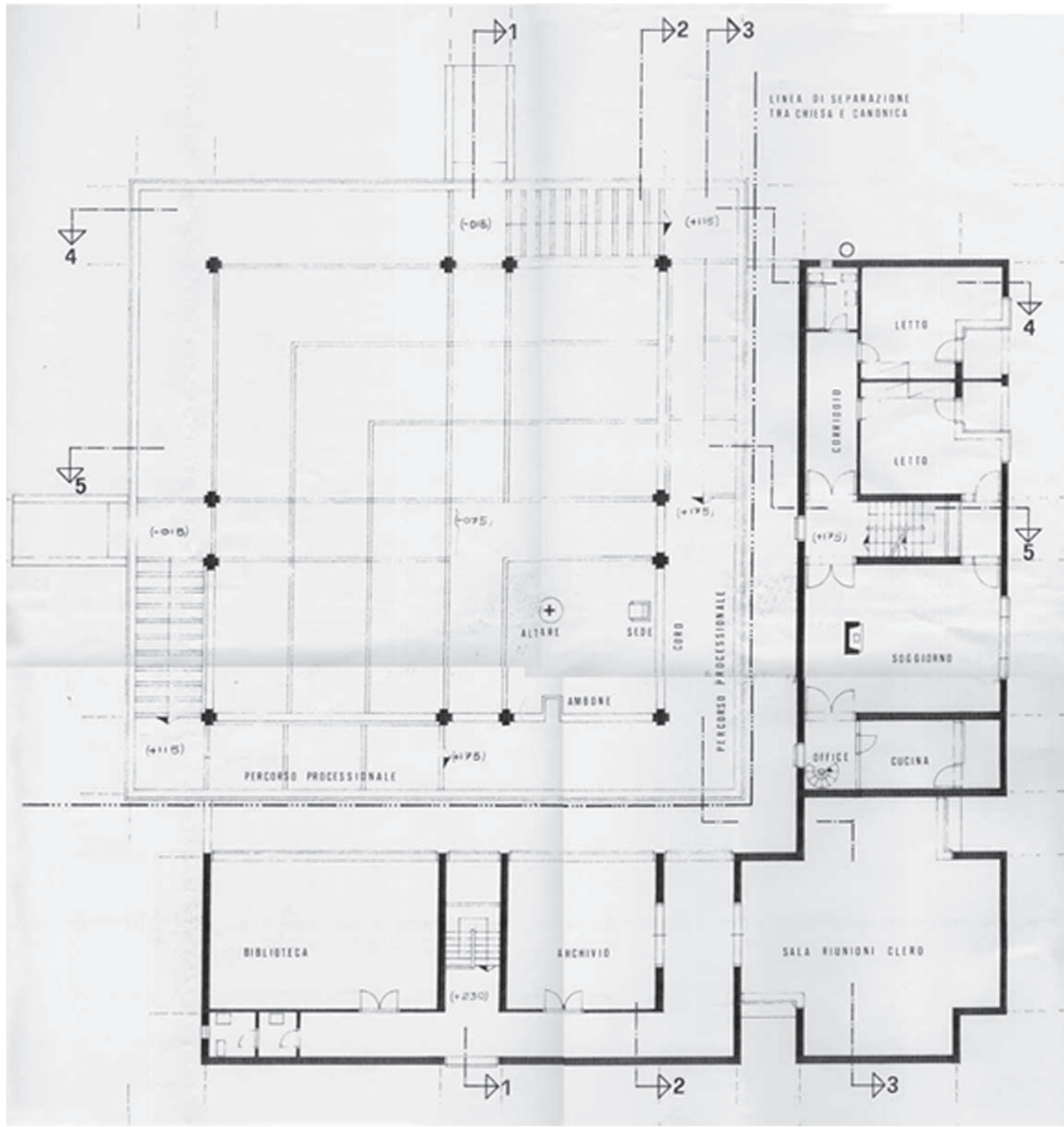

Fig. 10. Federico Gorio. Complejo parroquial en el barrio Cavedone (Bolonia, 1971/73). Planta alta 
nismos de acceso desde el exterior al interior. El paso del espacio exterior - el de la vida cotidiana - al interior - el espacio sacro- , ha de llegar a través de un elemento arquitectónico que subraye dicho paso. Para obtenerlo, Gorio reelabora en clave moderna el tema del pórtico cuádruple, colocándolo como elemento bisagra del doble recorrido de acceso. Desde el atrio arranca el camino del recorrido iniciático que conduce a la nave a través del pórtico cuádruple que custodia el baptisterio.

La presencia de un espacio arquitectónico utilizado como umbral, aumenta la sensación de valor de lo que está en el interior. La separación del interior a través de una clausura-bisagra con el exterior, subraya la dimensión profunda de la asamblea y de su importancia como centro conceptual del conjunto (Fig. 9).

En el diseño de Gorio, la asamblea se ha representado reunida en el interior del elemento principal y dispuesta según un esquema que se puede identificar con $e l$ anillo abierto conceptualizado algunos años antes por Rudolf Schwarz ${ }^{8}$. Con esta disposición centralizadora, la asamblea ha sido orientada al mismo tiempo tanto hacia el altar como hacia los circumstantes, recogiéndose toda ella en el interior de cuatro pilastras que sostienen el tiburio. Partiendo de uno de los lados de la nave, el presbiterio llega hasta el centro geométrico de la misma, donde se ha ubicado el altar'.

Resulta interesante la elección la posición del ambón, que a diferencia de las iglesias contemporáneas - donde este elemento arquitectónico se ha presentado siempre sobre la plataforma del presbiterio - se ha retirado de la misma y se ha ubicado en el espacio destinado a la asamblea de los fieles, restituyéndole así una presencia más destacada ${ }^{10}$. De este modo, el espacio arquitectónico proyectado por Gorio —o mejor dicho el espacio litúrgico-arquitectónico- consigue amparar del mejor de los modos «la liturgia de la Iglesia y la proclamación del mensaje de Jesucristo» ${ }^{11}$, dando una primera respuesta a la necesidad de integrar a todos los fieles en la plena, activa y consciente participación en las celebraciones litúrgicas, y que será establecida como dirección a seguir algunos años después, en el artículo 14 de la constitución litúrgica del Concilio Vaticano II.

$\mathrm{Y}$ aquí Gorio traduce perfectamente en arquitectura la nueva dimensión dinámica y comunitaria de la liturgia, el paso de pueblo a asamblea para significar los fieles reunidos para la celebración, según está expuesto en la comunicación introductoria del cardenal Lercaro en el I Congreso Nacional de Arquitectura Sacra ${ }^{2}$. Es interesante citar las palabras del cardenal Lercaro, pronunciadas en agosto de 1959, en las que describe su ideal de iglesia, y notar cómo estos conceptos acaban transformados en arquitectura por Federico Gorio al proyectar la iglesia del barrio de la calle Cavedone.

«Se me hace difícil imaginar una iglesia moderna sin un pronaos, una zona de respeto que permita el distanciamiento de las edificaciones profanas para introducir al contacto con el Señor y con sus hijos; me resulta más fácil imaginar el equivalente moderno de un pórtico cuádruple que hace posible una solemne procesión de entrada, para la cual siempre requeriré facilidad para desenvolverse a través de la iglesia. Incluso por una adhesión al espíritu de la liturgia, no podré imaginar el baptisterio y los confesionarios cerca del altar, en vez de cerca de la entrada; como por otro lado no sé imaginarlos, al menos el baptisterio, como demasiado angostos, tanto como para no permitir mínimamente a la comunidad el participar en el feliz evento de un nuevo hijo que viene a aumentar la familia. Más aún, no consigo ver un altar ahogado por poderosos retablos, tanto como para parecer más bien una repisa apoyada en una construcción monumental; no lo quiero demasiado alejado de la asamblea de los fieles, lo que convierte a los contactos, si no en imposibles, sí en difíciles y fríos» ${ }^{13}$.

Y precisamente esta capacidad de someter, de modelar la estructura sobre el contenido que nos revela el sentido profundo de las cosas, constituye, a mi parecer, la fuerza de la iglesia del barrio de la calle Cavedone: una nueva liturgia que conforma la estructura; el nuevo mensaje llega a convertirse en una arquitectura, en una forma que nace y responde exclusivamente a la nueva dinámica de la liturgia.

Los documentos custodiados en el archivo Gorio muestran los problemas económicos que ralentizaron el camino hacia la realización del proyecto, aplazándolo hasta los años setenta. Pero para entonces, en Bolonia las circunstancias ya eran otras; al cardenal Lercaro le ha sucedido el cardenal Poma, el cual, en una carta dirigida a Federico Gorio, expresa sus dudas acerca de la posibilidad de realización del proyecto desarrollado, sosteniendo que «el rumbo de la arquitectura sacra ha cambiado» ${ }^{14}$.

Gorio, queriendo llevar a cabo la realización de la iglesia, se pondrá a su completa disposición, y accederá a revisar el proyecto en profundidad. De hecho diseñará 
en poco tiempo un nuevo complejo parroquial (Fig. 10), mucho menos interesante que el anterior. Permanece la nave cuadrada, pero la asamblea queda dispuesta sobre la diagonal y en ligera pendiente descendente desde la entrada hasta el presbiterio, situado en un ángulo del cuadrado: un plano mucho más rígido que el precedente. No existe ya traza de aquel dinamismo espacial y litúrgico presente en el anterior proyecto, cuyo recuerdo se encomienda a un deambulatorio anular que rodea a la nave y que, saliendo lentamente, conduce al ambón colocado sobre el presbiterio en posición saliente.

Para pesar del proyectista, tampoco este proyecto llegará a realizarse. Durante un breve periodo se pensó en realizar una estructura prefabricada provisional, pero también se abandonó esta solución a sugerencia del propio Gorio, llegando a la decisión final de encaminar a los fieles a la cercana iglesia de san Juan Bosco, realizada por el arquitecto Giuseppe Vaccaro y finalizada pocos años antes. Esta decisión hizo desaparecer definitivamente el proyecto para la realización de una iglesia en el barrio de Cavedone.

\section{NOTAS}

(1) Con L. Quaroni, C. Aymonino, P.M. Lugli, G. Rinaldi, M. Valori, M. Ridolfi, C. Chiarini, M. Fiorentino, M. Lanza, S. Lenci, C. Melograni y S.C. Menichetti. Federico Gorio realizó el bloque A, donde se vio llevado por la urgencia de adjudicar la primera fase del núcleo edificatorio proyectado por él mismo para Eboli en 1949, y el bloque C, con G. Rinaldi.
(2) Matera, 1952. Con L. Agati, P.M. Lugli, L. Quaroni y M. Valori.

(3) Esta y otras referencias a continuación son pasajes extraídos de la memoria de proyecto consultada en el Archivo Gorio, carpeta 1.35.

(4) Loc. cit.

(5) Loc. cit

(6) Loc. cit.

(7) En la revista Chiesa e Quartiere 21 (1962) se publicó el proyecto de Gorio y Vittorini para la iglesia y complejo parroquial del barrio Ina-Casa de la calle Cavedone. En la ilustración 11 se han comparado dos versiones del proyecto, una de 1960 y la otra, publicada en la citada revista, y que presenta algunas modificaciones significativas.

(8) Cf. Roberto Masiero and Franco De Faveri (ed.), «Rudolf Schwarz. Costruire la Chiesa. Il senso liturgico nell'architettura sacra», Morcelliana, Brescia, 1999. Este texto propone la traducción de la obra de Rudolf Schwarz «Von bau der kirche», de 1938.

(9) Cf. Karl Richter, "Comunità, spazio liturgico e altare», en VVAA, «L'Altare» (Atti del II Convegno Liturgico Internazionale), Qiqajon, Bose, 2003; pág. 183-200.

(10) Cf. Albert Gerhards, «La liturgia come incontro con Cristo: conseguenze per lo spazio liturgico», en VVAA., «L'Ambone» (Atti del III Convegno Liturgico Internazionale), Qiqajon, Bose, 2005; pág. 219-238.

(11) Cf. Johannes Krämer y Walter Zahner, «Realizzazioni di spazi liturgici in Germania. Analisi liturgia e architettonica», en VVAA., Spazio liturgico ed orientamento (Atti del IV Convegno Liturgico internazionale), Qiqajon, Bose, 2006; pág. 63-83.

(12) Cf. Maria Beatrice Bettazzi, «Millenovecentocinquantacinque. L'esordio del movimento bolognese per l'architettura sacra moderna», en: VVAA, «Chiesa e Quartiere. Storia di una rivista e di un movimento per l'architettura a Bologna», Compositori, Bologna, 2004; pág. 38-48.

(13) Discurso de Giacomo Lercaro pronunciado en la Universidad de Notre-Dame (Indiana, EEUU), durante la entrega de premios del concurso para una iglesia parroquial con motivo de la XX Semana Litúrgica (24-29 de agosto de 1959), en: Elio Guerriero y Antonio Tarzia (ed.), «Giacomo Lercaro. La chiesa nella città. Discorsi e interventi sull'architettura sacra», San Paolo, Cinisello Balsamo, 1996; pág. 65-71.

(14) Archivo Gorio, carpeta 1.35. Carta con firma del Secretario del cardenal A. Poma, fechada el 13 de mayo de 1971. 